\title{
AIR POLLUTION AND MORBIDITY IN DUBLIN
}

\author{
JOHN C. SWEENEY \\ Department of Geography \\ St Patrick's College, Maynooth
}

\begin{abstract}
Ground level concentrations of smoke and sulphur dioxide in Dublin approach, and on occasion exceed, values at which the World Health Organisation suggest adverse health effects may be discerned. To examine the alleged threshold position of the city in this respect hospital admission data for three winter periods from 1975 to 1978 are examined in conjunction with climatic and air pollution data for the corresponding period. Significant associations are found between sulphur dioxide levels and respiratory and cardiovascular morbidity for the first winter studied, and between smoke levels and respiratory categories for the remaining two. Inferential deduction following multivariate analysis suggests unfavourable dispersion conditions were influential during the second winter and significant changes in the emission environment were involved during the third winter period. It is suggested that the initial effects of changing consumer fuel preference from oil to solid fuel are apparent in the relative decline of $\mathrm{SO}_{2}$, compared with smoke, as the key pollution variable with respect to morbidity and that an end to the relative neglect of this pollution parameter would now be appropriate.
\end{abstract}

The adverse effects on health of exposure to high levels of air pollution have for long been widely recognised. As early as 1306 Edward I of England outlawed the burning of coal for this reason, and even went so far as to execute a violator of his decree the following year (Edelman, 1968). In Dublin the possibility that pollutant concentrations were high enough to induce or exacerbate ill health was acknowledged in 1729 by Jonathan Swift. Writing in the Weekly fournal of 'the smoke which in winter is so thick [and] has so great an influence that it affects even the blossom and bloom of the flowers in spring', he goes on to note how the Dublin physicians 'made it their constant practice to remove their patients to the purer air near the suburbs out of the smoke of the city' (Swift, 1729).

In the two and a half centuries since then, the problem has persisted. During the 1960s De Wytt and Kevany (1971) found smoke and sulphur dioxide concentrations on occasion to be above levels at which the World Health Organisation suggests health effects become apparent. Indeed some such effects were detected in a later study (Kevany et al., 1975) which found significant correlations between respiratory and cardiovascular mortality and morbidity and daily averages of sulphur dioxide based on a network of eight monitors in central Dublin. Furthermore, a relatively low threshold, $100 \mu \mathrm{g} / \mathrm{m}^{3}$, is suggested above which statistically significant increases occurred.

The most recent study of the association between air pollution and health in Dublin by Bailey et al. (1978) relates to the winter periods from 1973 to 1975 . A statistically significant relationship is found for only the first winter studied. For the remaining two, climatic influences are instead found to give a 
better explanation of the weekly variances in mortality and morbidity for respiratory and cardiovascular diseases. Accordingly it was suggested that, as a result of generally declining levels of air pollution during the first half of the 1970 s, Dublin was then in a threshold position whereby a climatically unfavourable winter was required to produce enhanced pollution concentrations and hence significant health effects.

Such a conclusion may no longer be valid. Since the mid 1970s, farreaching changes have taken p ace in the importance of specific categories of air pollution in Dublin. If the twelve Dublin Corporation monitors are considered for example, their ratio of smoke to sulphur dioxide concentrations was typically 0.5 in $1973 / 74$. In $1980 / 81$ the ratio was 0.9 , which is indicative of an increased contribution from smoke pollution of domestic origin, and a reflection of rapidly changing consumer fuel preference. Consequently extrapolation of trends derived on the basis of former time periods may be misleading. There is thus a need to reassess the relationship between levels of air pollution and health, with a view to more efficient air quality management in future years.

\section{Data and methods}

Two independent monitoring networks for smoke and sulphur dioxide exist in Dublin, maintained by the Electricity Supply Board and Dublin Corporation respectively. The majority of sites utilise the automatic 8-day sampler, in the case of the former on a midnight to midnight basis, and for the latter, during the period studied, from midday to midday. While such a time lag renders daily comparisons of data between the two networks impossible, over a weekly time period it is not significant, enabling both networks to be employed in constructing a weekly pollution index.

Obvious deficiencies involved in the employment of pollution indices must be acknowledged. These relate to the extent to which the network is representative of conditions at the neighbourhood and city scales. Bailey and Walsh (1980) point to poor correlations, particularly for sulphur dioxide, between Dublin sites in relatively close proximity, while the spatial bias of the network is clearly apparent from Figure 1 where a dearth of monitoring sites in the rapidly growing western urban area can be seen. Notwithstanding these limitations weekly averages of smoke and sulphur dioxide from a network of up to 36 monitors for the October-March periods from 1975 to 1978 were computed.

Data on hospital admissions were obtained from the Hospital In-Patient Enquiry Scheme of the Medico-Social Research Board. A selection of those patients admitted for respiratory or cardiovascular complaints was made according to the numerical classification of disease employed by the World Health Organisation (W.H.O., 1967). Admissions from outside Dublin were excluded, leaving over 16,000 cases relevant to the present study. These were chronologically sorted into weekly totals to control for the marked day of the week cycle apparent in hospital admissions. Aggregation into longer time periods would have been preferable. Monthly intervals, for example, would have enabled greater allowance for the inevitable time lag between onset of disease and hospital admission, though the nature of this relationship is not clear. Certainly a distinction might well be apparent between cardiovascular admissions, more acute in nature, and the exacerbation of chronic respiratory 


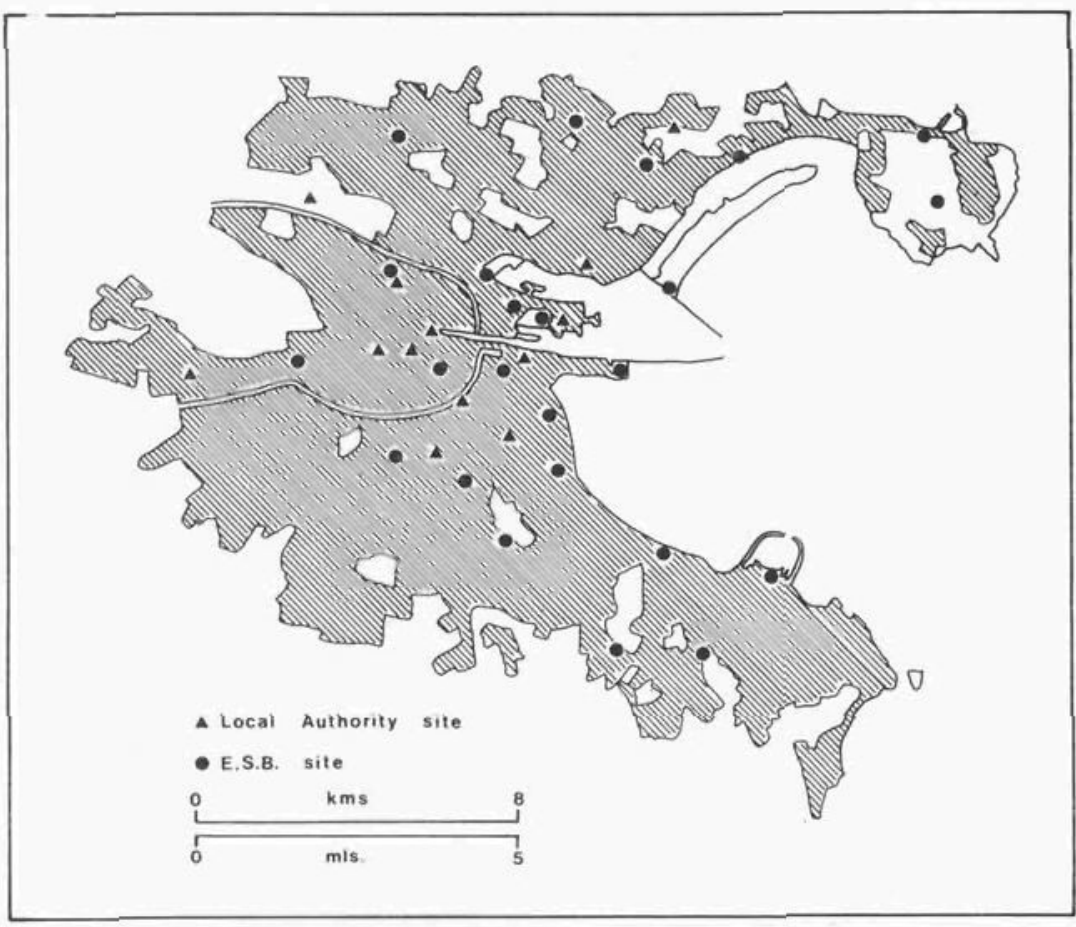

Figure 1. Air pollution monitoring sites in Dublin.

symptoms which might be expected to show a longer lag time. Weekly intervals, however, were the only practicable choice for the length of time studied. Their suitability or otherwise would require further analysis extending over several winter periods of data.

Climatological data for the corresponding time periods were also merged on to the database. This was derived from hourly observations at Dublin Airport from which weekly averages were computed for maximum and mean daily temperature, wind speed and relative humidity. Temperature was considered to be a possible important influence on fuel consumption and hence potential pollutant emissions. Maximum temperature, in addition to this role, could be considered indicative of conditions during the important day time period when decisions regarding fuel usage are made. Some association with the relative buoyancy of the air, an important influence on ground level concentrations, might also be expected. The dispersal of pollutants is known to be strongly influenced by wind speed (Leone et al., 1966) and their removal from the atmosphere closely connected to the condensation mechanism (Bach, 1972). Accordingly, wind speed and relative humidity parameters were also included. The observations were assumed to be representative of urban conditions despite the occasional existence of heat island effects (Cumiskey, 1979).

Before proceeding to an analysis of the associations apparent in these three data sets, it is appropriate to bear in mind the contention by Blalock (1964) that causality can never be demonstrated for correlational data, or indeed for 
any type of empirical information. Causal inferences can, however, be hypothesised concerning the additive or synergistic role, for example, of air pollution in combination with other variables which contribute to ill-health. It is in fact the practical impossibility of controlling for all these other variables, among them housing, cigarette smoking and social class, which justified Blalock's contention. For this investigation control of only one external variable is attempted, that of the climatic environment, or rather some aspects of it. This is done using the multiple regression technique with a view to determining whether associations between morbidity and concentrations of smoke and sulphur dioxide are in fact spuriously reflecting a simultaneous climatic influence on both sets of variables.



Figure 2. Weekly averages of data values, Winter 1975/76. 


\section{Results}

Temporal variations in the two pollution and three morbidity indicators for each of the three winters can be seen in Figures 2 to 4. For 1975/76, total weekly admissions are seen to peak the week following the highest sulphur dioxide value, largely as a result of respiratory cases. Fewest admissions, on the other hand, do not appear to be associated with lower than normal smoke or sulphur dioxide values during the preceding weeks; rather they appear to be largely attributable to the effects of the Christmas period, a feature also evident the following winter. For 1975/76, a close correlation between respiratory and total admissions is apparent and, since cardiovascular admissions are fairly constant throughout the period, the ratio of respiratory to cardiovascular admissions increases as the winter progresses. For the following winter maximum hospital admissions and maximum smoke concentration

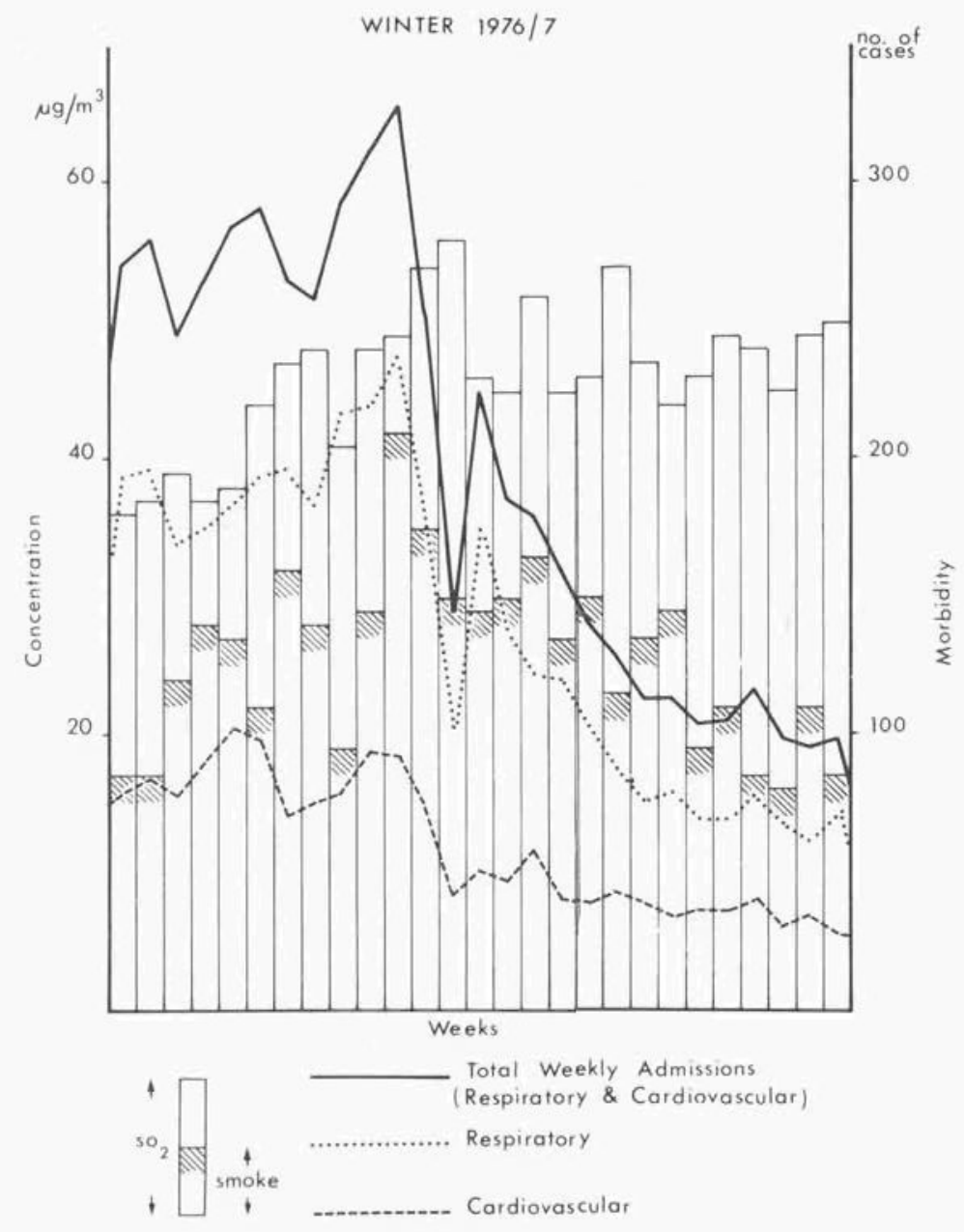

Figure 3. Weekly averates of data values, Winter 1976/1977 
occur in the same week. No lag effect is apparent, raising again the problem mentioned earlier of the time units used in the analysis. For this year there is a noticeable degree of agreement apparent between both categories of morbidity and smoke concentrations. By contrast the sulphur dioxide trend appears to move in an opposite direction to morbidity. The peak for weekly sulphur dioxide coincided with the Christmas drop in admissions. During 1977/78, no dominant peak in total admissions is apparent. The most detectable peak is seen a week after peak sulphur dioxide, while a secondary one occurs before the turn of the year the same week as the peak for weekly smoke. Other than this, trends appear more poorly developed than in either of the other two winters.

Quantification of these relationships can be seen in Table 1. In each of the three winters total morbidity achieves a correlation coefficient of approximately 0.5 with one or other pollution index, significant at the $99 \%$ level or above. For 1975-76, sulphur dioxide is the better pollution variable, with no significant correlations being observed between any of the morbidity classes and any of the climatic variables. Mean sulphur dioxide levels were highest during this winter, and it may be suggested therefore that sulphur dioxide had

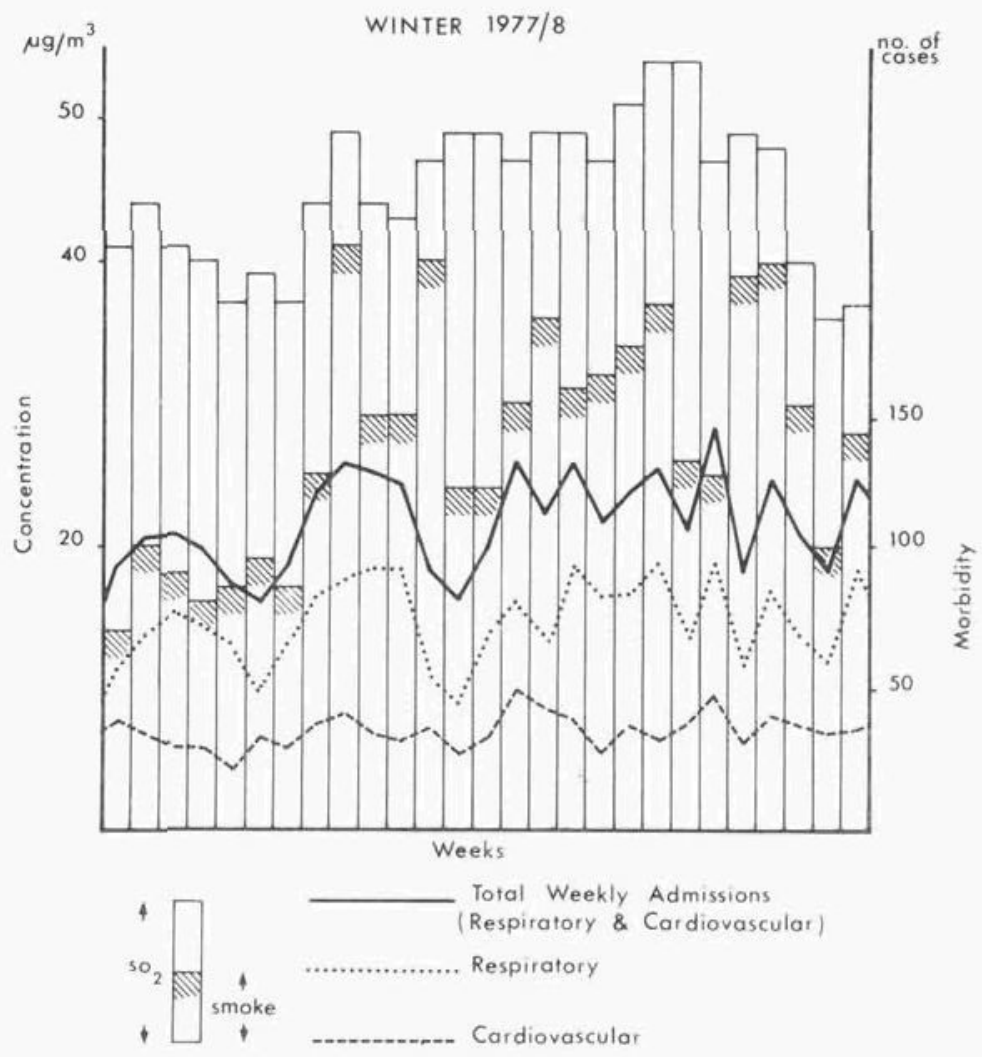

Figure 4. Weekly averages of data values, Winter 1977/78 
a significant effect on both respiratory and cardiovascular hospital admissions during this winter.

For the remaining two winters a more complex explanation seems appropriate. In both cases smoke concentrations are highly significant, particularly with respect to respiratory admissions. Even higher correlations are observed, however, with the climatic variables, and it is not clear whether intercorrelation between smoke and climatic variables is responsible for the high correlations between morbidity and smoke. In order to examine this a stepwise multiple regression was carried out, yielding nine regression equations. Although a similar procedure was adopted in some of the earlier studies already reviewed, there are a number of serious limitations inherent in the use of the multiple regression technique in this instance. Principally these relate to the time series nature of the data and the problem that data values from week to week may be correlated with each other. An examination of the autocorrelation functions suggested that this was the case. for some of the series and so the use of a time series model which allowed for lagged correlations (Box and Jenkins, 1970) was investigated. Findings, however, differed little from those of the multiple regression model, which was consequently retained, and for which the results can be seen in Table 2 .

For $1975 / 76$, sulphur dioxide was the first variable selected by the stepwise regression, and, at the $p=0.01$ level, is the only statistically significant variable for all three morbidity categories. At the $p=0.05$ level, sulphur dioxide remains the only significant variable with respect to respiratory morbidity, and is also significant for cardiovascular admissions. Therefore, despite the apparent importance of climatic considerations such as wind and

TABLE 1

WEEKLY CORRELATIONS BETWEEN MORBIDITY, CLIMATIC ANI POLLUTION VARIABLES

\begin{tabular}{lcrrrrr}
\hline \multicolumn{1}{c}{ Category } & Smoke & $\mathrm{SO}_{2}$ & Wind & Temp. & Max.Temp. & R.Hum. \\
\hline 1975/76 & & & & & & \\
Total Morbidity & 0.29 & $0.49^{\star}$ & 0.29 & -0.27 & -0.26 & 0.19 \\
Cardiovascular & 0.18 & $0.44^{\star}$ & 0.32 & -0.17 & -0.19 & 0.37 \\
Respiratory & 0.29 & $0.43^{\star}$ & 0.22 & -0.26 & -0.26 & 0.09 \\
1976/77 & & & & & & \\
Total Morbidity & $0.49^{\star}$ & 0.06 & $-0.60^{\star}$ & -0.12 & -0.15 & $0.52^{\star}$ \\
Cardiovascular & 0.37 & -0.11 & $-0.62^{\star}$ & 0.04 & -0.09 & $0.51^{\star}$ \\
Respiratory & $0.52^{\star}$ & 0.13 & $-0.57^{\star}$ & -0.18 & -0.20 & $0.51^{\star}$ \\
1977/78 & & & & & & \\
Total Morbidity & $0.48^{\star}$ & 0.18 & -0.16 & $-0.49^{\star}$ & $-0.51^{\star}$ & 0.21 \\
Cardiovascular & 0.42 & 0.20 & -0.24 & -0.39 & -0.38 & 0.10 \\
Respiratory & $0.42^{\star}$ & 0.15 & -0.10 & $-0.44^{\star}$ & $-0.47^{\star}$ & 0.21 \\
\hline
\end{tabular}

*Correlations significant at the $99 \%$ level 
maximum temperature, it seems reasonable to conclude that sulphur dioxide was a relatively important factor in cardiovascular and respiratory hospital admissions for this period.

For $1976 / 77$, mean weekly wind speed emerges as the only variable which was highly significant. Despite being highly significant when correlated individually with morbidity, smoke and relative humidity did not add to the explanation of the variance in any of the morbidity categories following the inclusion of wind speed. Accordingly, it may be suggested that whereas a straightforward pollution-morbidity relationship may have been apparent in $1975 / 76$, climatic conditions were the most significant features of 1976/77. The high negative correlation obtained between morbidity and wind speed suggests that low windspeeds may have been associated with increases in morbidity, while the high positive correlation with humidity suggests that such increases in morbidity may also have been associated with periods of higher than average humidity. This suggestion is strengthened if the climatic data for $1976 / 77$ is averaged and compared with that for the other two winters. The winter of 1976/77 is found to have the lowest average windspeed and highest average humidity of the three winters. A greater than normal incidence of such calm, humid conditions would reflect a more frequent occurrence of surface based, or low level, inversions of temperature, seasonal variations in which are a feature of Irish climatology (Sweeney, 1979). While information on the incidence and persistence of these occurrences is inadequate for the Dublin area, they are of considerable importance in producing higher than normal pollution concentrations. This arises from the fact that less buoyant,

TABLE 2

MULTIPLE REGRESSION RESULTS

\begin{tabular}{|c|c|c|c|c|}
\hline Year & Category & Variables in equation (F-ratio) & $\begin{array}{l}\text { Significant } \\
\text { variables } \\
p=0.05\end{array}$ & $\begin{array}{l}\text { Multiple } \\
\text { correlation } \\
R\end{array}$ \\
\hline \multirow{3}{*}{$\begin{array}{r}1975 / \\
1976\end{array}$} & Total Morbidity & $\mathrm{SO}_{2}(2 \cdot 76), \mathrm{W}(5 \cdot 23), \mathrm{S}(3 \cdot 27)$ & W & 0.61 \\
\hline & Cardiovascular & $\begin{array}{l}\mathrm{SO}_{2}(5 \cdot 30, \mathrm{~W}(9 \cdot 17), \mathrm{MAX} . \mathrm{T}(4 \cdot 24) \\
\mathrm{S}(2 \cdot 33), \mathrm{R} . \mathrm{HUM}(1 \cdot 33)\end{array}$ & $\begin{array}{l}\mathrm{SO}_{2}, \mathrm{~W} \\
\mathrm{MAX} . \mathrm{T}\end{array}$ & 0.68 \\
\hline & Respiratory & $\mathrm{SO}_{2}(6 \cdot 28)$ & $\mathrm{SO}_{2}$ & 0.43 \\
\hline \multirow{3}{*}{$\begin{array}{r}1976 / \\
1977\end{array}$} & Total Morbidity & $\mathrm{W}(8 \cdot 07), \mathrm{S}(2 \cdot 30)$ & w & 0.63 \\
\hline & Cardiovascular & $\mathrm{W}(5 \cdot 51), \mathrm{R} \cdot \mathrm{HUM}(1 \cdot 88), \mathrm{SO}_{2}(0 \cdot 77)$ & W & 0.66 \\
\hline & Respiratory & $\mathrm{W}(6 \cdot 05), \mathrm{S}(3 \cdot 62)$ & W & 0.63 \\
\hline \multirow[t]{3}{*}{$\begin{array}{r}1977 / \\
1978\end{array}$} & Total Morbidity & $\begin{array}{l}\operatorname{MAX} . \mathrm{T}(5 \cdot 68), \mathrm{R} . \mathrm{HUM}(2 \cdot 27) \\
\mathrm{SO}_{2}(2 \cdot 88), \mathrm{S}(1 \cdot 68)\end{array}$ & MAX.T & 0.63 \\
\hline & Cardiovascular & $S(6 \cdot 28)$ & $S$ & $0 \cdot 42$ \\
\hline & Respiratory & $\begin{array}{l}\operatorname{MAX} . \mathrm{T}(10 \cdot 91), \mathrm{R} . \operatorname{HUM}(3 \cdot 57), \\
\quad \mathrm{SO}_{2}(2 \cdot 22)\end{array}$ & MAX.T & 0.57 \\
\hline
\end{tabular}

Note: $\mathrm{W}=\mathrm{W}$ ind; $\mathrm{S}=$ Smoke 
low level, smoke emissions, originating mainly from domestic sources, would be trapped by low level inversions, leading to enhancement of ground level concentrations, while sulphur dioxide, characteristically emitted at a considerable height and at a high temperature, would be less inclined to accumulate close to ground level. Such a scenario would explain why, in Table 1 , weekly smoke values correlate well with the three morbidity categories while sulphur dioxide does not.

The winter of $1977 / 78$ also shows only one significant variable after multiple regression; maximum temperature for respiratory, and smoke concentrations for cardiovascular morbidities. That the former factor is by far the more important is seen by its dominant contribution to the total morbidity category. Smoke, sulphur dioxide, and the other climatic variables do not add significantly to the explanation of variance provided by maximum temperature, despite the fact that smoke concentrations were higher this winter than during the previous two. The reason for this does not appear to relate to increased trapping; this was the windiest of the three winters. Relatively high smoke values accompanying climatic conditions favourable for dispersal thus render this winter anomalous relative to its two preceding ones. This is also apparent when the mean maximum temperatures of the three winters are compared; that of $1977 / 78$ is found to be unremarkable, and of intermediate value to the other two.

It is suggested that the cause of higher smoke concentrations in a winter apparently more favourable for pollution dispersal can only be a substantial increase in smoke emissions. Accordingly, maximum temperature may well be acting as a surrogate measure of smoke emissions, illustrating the well known inverse relationship between temperature and fuel consumption (Elsom, 1976). For this winter the increase in emissions is apparently sufficient to offset any reduction in ground level concentrations which the more favourable climatic environment would otherwise have induced. This has important implications for both respiratory and cardiovascular morbidity during climatically unfavourable winters.

\section{Conclusions}

The evidence presented is indicative of the relatively important role played by air pollutants in influencing cardiovascular and respiratory hospital admissions in Dublin during a time of change in the city's pollution environment. The strong correlations between sulphur dioxide and health indicators which were apparent in earlier studies (Kevany et al., 1975; Bailey et al., 1978) have been identified only for the first winter period studied. Since then smoke appears to have displaced sulphur dioxide as the pollutant most influential in relation to morbidity fluctuations. This relationship is, however, only apparent on one of the winter records as a result of a dominant climatic influence expressed in terms of a greater incidence of stagnating circulations in the lower atmosphere. In this context, Dublin could be said to be in the threshold position ascribed to it by Bailey et al. (1978), whereby significant health effects require climatically induced pollution enhancement.

For the most recent period studied, however, the effect of the (until recently government subsidised) flight from oil is apparent in a morbidity-smoke relationship reflecting the effect of increasing smoke emissions. Latest projections (Kavanagh and Brady, 1980) suggest that coal will displace oil as Ireland's 
primary energy source within the next two decades. In the absence of some clean air policy for domestic emissions, therefore, the health-pollution relationship may in future be rather easier to study, particularly in winters characterised by the presence of strong subsidence inversions of temperature.

Bach, W.

Bailey, M.L., Kevany, J.P., and Walsh, J.J.

Bailey, M.L. and Walsh, J.J.

Blalock, H.M.

Box, G.E.P., and Jenkins, G.M.

Cumiskey, J.

De Wytt, C., and Kevany, J.

Edelman, S.

Elsom, D.

Kavanagh, R., and Brady, J.

Kevany, J., Rooney, M., and Kennedy, J.

Leone, I.A., Brennan, E., and Daines, $\mathrm{R}$.

Sweeney, J.C.

Swift, J.

World Health Organisation

\section{REFERENCES}

1972 Atmospheric pollution, New York

1978 Air pollution, climate and health in Dublin, National Board for Science and Technology, Dublin.

1980 'Monitoring of air pollutants in Dublin', Ir. F. Environ. Sci., 1, 26-36.

1964 Causal inference in non-experimental research, Chapel Hill.

1970 Time series analysis, San Francisco.

1979 The application of remote sensing techniques in the study of small town climatology, unpublished M.Sc. thesis, University College, Dublin.

1971 'Air pollution in Ireland', Ir. f. med. Sci., 140, 108-117.

1968 'Air pollution control legislation', in Stern, A.C. (ed.), Air pollution, 2nd edition, Vol. 3, New York.

1976 'Meteorological controls upon ground level concentrations of smoke and sulphur dioxide in the Manchester area', paper presented at the Association of British Climatologists' Meeting, Institute of British Geographers, Coventry, January 6-10.

1980 Energy supply and demand - the next thirty years, National Board for Science and Technology, Dublin.

1975 'Health effects of air pollution in Dublin', Ir. F. med. Sci., 144 (3), 102-115.

1966 'The role of wind parameters in determining $\mathrm{SO}_{2}$ concentrations in Carlstadt, New Jersey', Int. f. Air. Wat. Pollut., 7, 473-500.

1979 'Inversion persistence at Long Kesh, Northern Ireland', Weather, 34(2), 50-59.

1729 'The case of many thousand poor inhabitants of this city', Dublin Weekly fournal, 2(27), 109-110.

1967 International classification of diseases, injuries and cause of death, 8th revision, Geneva. 